\title{
Electric Control Substituting Pitch Control for Large Wind Turbines
}

\author{
Jon Kjellin, Sandra Eriksson, and Hans Bernhoff \\ Division of Electricity, Swedish Centre for Renewable Electric Energy Conversion, Uppsala University, \\ Box 534, 75121 Uppsala, Sweden
}

Correspondence should be addressed to Sandra Eriksson; sandra.eriksson@angstrom.uu.se

Received 8 May 2013; Revised 15 August 2013; Accepted 20 August 2013

Academic Editor: Ujjwal K. Saha

Copyright (C) 2013 Jon Kjellin et al. This is an open access article distributed under the Creative Commons Attribution License, which permits unrestricted use, distribution, and reproduction in any medium, provided the original work is properly cited.

A completely electrical control of a variable speed wind turbine is experimentally verified. A vertical axis wind turbine with a direct driven generator and an electrical system with diode rectification and full inverter connected to the electric grid is presented. This is the first paper that presents this novel $200 \mathrm{~kW}$ wind power plant erected at the west coast of Sweden. The turbine has fixed pitch and is only controlled electrically accommodated by passive stall of the blades. By electrically controlling the generator rotational speed with the inverter, passive stall regulation is enabled. The first results on experimental verification of stall regulation in gusty wind speeds are presented. The experiments show that the control system can keep the turbine rotational speed constant even at very gusty winds. It is concluded that electrical control accommodated by passive stall is sufficient as control of the wind turbine even at high wind speeds and can substitute mechanical control such as blade pitch.

\section{Introduction}

Increased amount of electricity produced from wind power is one of the ways to reach the goal of lowering emissions of greenhouse gases from energy production. Installed wind turbines and wind power plants have increased both in size and number in the last 25 years. However, research is still needed, in order to increase the reliability of turbines [1]. The research in wind power at the division of electricity at Uppsala University is focused at vertical axis wind turbines of straight-bladed Darrieus type. Darrieus turbines are described in [2]. The novel concept with an all-electric control and a variable speed turbine connected to a direct driven PM generator placed on ground reduces the number of moving parts compared to conventional wind turbines. Hence, the maintenance cost is expected to be lower than for conventional wind turbines. The turbine is controlled electrically by controlling the power output and rotational speed of the generator; that is, no mechanical control as described in [3] is needed. In wind speeds above nominal, the electrical system is accommodated by passive stall. Passive stall has also been used historically in fixed speed horizontal axis wind turbines [4]. However, in this concept it is used together with a variable speed turbine instead of fixed speed.

In conventional horizontal axis wind turbines, the gearbox, pitch, and yaw system stand for a substantial part of the downtime [5]. Further, by placing the generator on ground, it is easier to mount and maintain it. The generator can be designed for robustness and efficiency in the absence of weight and volume constraints. Additionally, recent results indicate that vertical axis turbines can perform better in parks than horizontal axis turbines [6]. The first experimental research started in 2006 when a $12 \mathrm{~kW}$ turbine was erected north of Uppsala [7, 8]. In 2010 a first commercial $200 \mathrm{~kW}$ turbine based on the same concept was erected and grid connected in Falkenberg at the west coast of Sweden, Figure 1, by Vertical Wind $\mathrm{AB}$ a spin-off company from Uppsala University. The $200 \mathrm{~kW}$ turbine was built as a scaled-down prototype of a multi-MW turbine. This is the first paper that presents experimental results from the $200 \mathrm{~kW}$ turbine built with this novel concept. The paper presents an experimental verification of the electric control accommodated by passive stall during gusty wind speeds above nominal wind speed. 


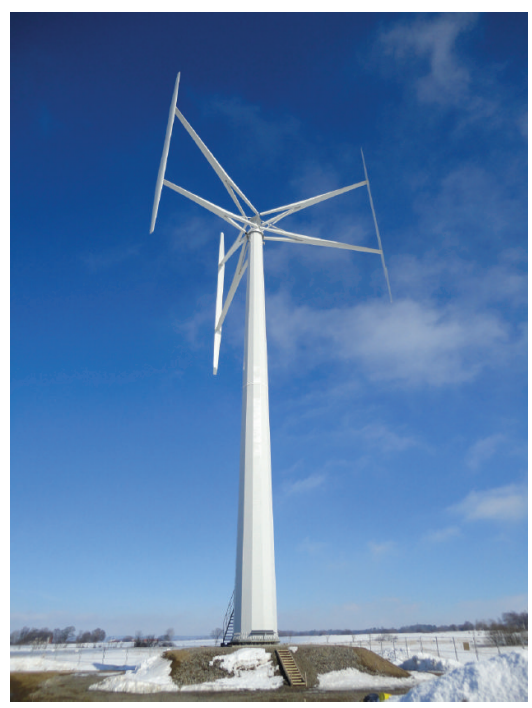

FIGURE 1: The $200 \mathrm{~kW}$ wind turbine used in the experiment.

\section{Theory}

The power absorption, $P_{\text {mech }}$, of a wind turbine is described by

$$
P_{\text {mech }}=\frac{1}{2} \rho A v^{3} C_{P}=C_{P} P_{\text {wind }} \text {, }
$$

where $\rho$ is the air density, $A$ is the projected area, $v$ is the wind speed and $C_{P}$ is the power coefficient. $P_{\text {wind }}$ is the power available in the wind. $C_{P}$ depends on the tip speed ratio, $\lambda$, which is described by

$$
\lambda=\frac{\omega R}{v},
$$

where $\omega$ is the rotational speed and $R$ is the turbine radius. The theoretical curve for this specific turbine was found from simulations based on [9]; see Figure 2. This figure has not been experimentally verified yet, and therefore the axes do not have scales. It serves as a representation of the behaviour of the $C_{P}-\lambda$ curve.

During operation, the absorption of the turbine is regulated by altering the tip speed ratio of the turbine. For wind speeds lower than rated $(12 \mathrm{~m} / \mathrm{s})$, the control system aims at keeping an optimal tip speed ratio to maximize the absorption. As the tip speed ratio decreases, the turbine stalls and the power absorption is reduced. For wind speeds close to rated wind speed and higher, the tip speed ratio is decreased to assure constant power absorption from the turbine. In this region the tip speed ratio is regulated to decrease power output for increasing wind speeds; that is, the turbine is stall regulated. The turbine is controlled to always operate on optimal tip speed ratio or lower to ensure stable operation which in the figure corresponds to the part of the graph placed to the left of the dashed line. For this turbine the optimal tip speed ratio is expected to be between 3.5 and 4 , and the corresponding $C_{P}$ is expected in the region of $0.35-$ 0.4 .

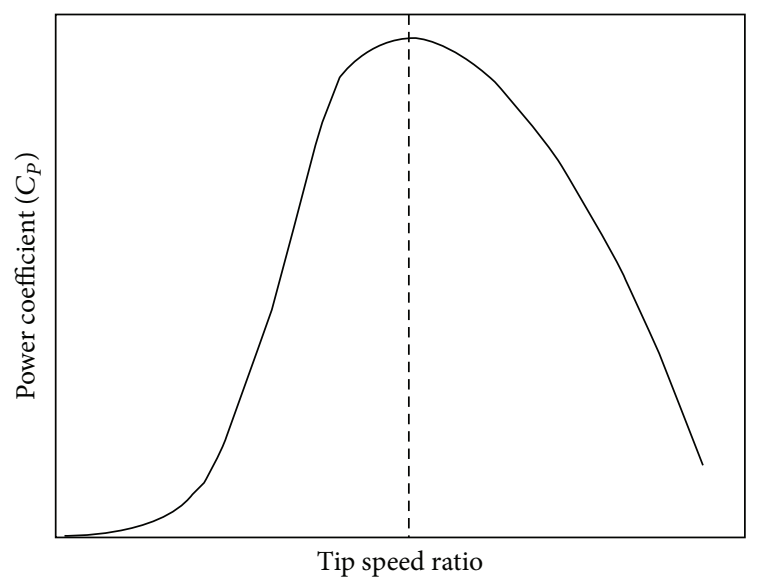

Figure 2: The relationship between $C_{P}$ and tip speed ratio. The dashed line indicates the optimal tip speed ratio.

TABLE 1: Nominal properties of the wind turbine.

\begin{tabular}{lc}
\hline Power $(\mathrm{kW})$ & 200 \\
Rotational speed $(\mathrm{rpm})$ & 33 \\
Blade tip speed $(\mathrm{m} / \mathrm{s})$ & 45 \\
Wind speed $(\mathrm{m} / \mathrm{s})$ & 12 \\
Number of blades & 3 \\
Swept area $\left(\mathrm{m}^{2}\right)$ & 624 \\
Hub height $(\mathrm{m})$ & 40 \\
Turbine radius $(\mathrm{m})$ & 13 \\
Blade length $(\mathrm{m})$ & 24 \\
Aerodynamic control & Passive stall
\end{tabular}

\section{Method}

3.1. The Wind Turbine. The $200 \mathrm{~kW}$ turbine consists of three 24 meter long straight blades with a standard NACA profile; see Table 1. Each blade is connected to two streamline-shaped struts bolted to the hub. The blades and struts are made from glass fiber. The turbine is mounted on a $40 \mathrm{~m}$ high conical tower that encases and carries the shaft connecting the turbine and generator.

The generator design is adapted to the torque and rotational speed of the turbine without the use of a gearbox. It is designed to have good over load capacity with a load angle of 9.9 degrees at nominal operation and can thereby handle the turbine in all possible operational conditions. The 36-pole rotor is permanently magnetized with $\mathrm{NdFeB}$ magnets. The stator is cable wound with $50 \mathrm{~mm}^{2}$ PVC insulated stranded copper conductors. At nominal operation the three phase generator delivers a line-to-line voltage of $839 \mathrm{~V}$ and a current of $160 \mathrm{~A}$ at an electrical frequency of $9.9 \mathrm{~Hz}$. The efficiency of the generator is calculated to $96.7 \%$. The design of the generator and its overload capacity are further described in [10].

The turbine does not have any moving parts such as pitch control; instead absorption is electrically controlled by the generator which controls the rotational speed of the turbine. The turbine is grid connected through an electrical system. 


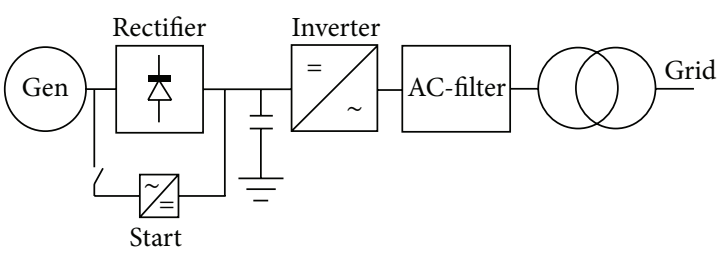

Figure 3: Layout of the electrical system from generator to grid. Parallel to the rectifier is a small inverter used for starting the turbine.

All parts of the electrical system, except the generator, are placed in a nearby substation where the three-phase current from the generator is rectified to a capacitor-stabilized DCbus connected to a three-phase inverter. The rectifier is a passive diode bridge. The voltage over the DC-bus varies with the rotational speed of the generator and is controlled by the inverter, which thereby also controls the rotational speed of the turbine. The operating voltage span of the DC-bus is from $520 \mathrm{~V}$ up to $950 \mathrm{~V}$ which corresponds to a span of 15 to $30 \mathrm{rpm}$ in rotational speed. The present wind speed together with the desired tip speed ratio is used to calculate a set point for the $\mathrm{DC}$ voltage. The difference from the present $\mathrm{DC}$ voltage and the output from a PLL (phase locked loop) control the PWM (pulse width modulation) output of the inverter. Figure 3 shows the basic layout of the electrical system.

3.2. Measurement Setup. All experimental data was logged by the LabVIEW Compact RIO based control system of the turbine. The sampling frequency for measurements is $1 \mathrm{~Hz}$. The wind speed is measured in a nearby measurement tower, which is placed at hub height $100 \mathrm{~m}$ from the wind turbine according to the international standard for power performance measurements [11]. The anemometer used is a Thies Clima 4.3351.00.161. The rotational speed of the turbine is measured by a 10 bit rotational encoder placed on the drive shaft. The power is measured as the DC power delivered from the turbine after rectification measured by a Tektronix P5200 for voltage and a SSET CEIZ04-55E4-1.0/0-400 A for current. All experimental results are shown as $20 \mathrm{~s}$ sliding averages of data to reduce the effects of the difference in wind speed at the turbine and the measurement tower and to improve readability of figures.

3.3. Experiment. In order to verify that the passive stall control worked as expected, an experiment at fixed rotational speed and very turbulent winds was performed. During the experiment no power tracking algorithms were used; instead the rotational speed was set manually to a constant level by fixating the rectified DC-voltage from the generator. This method keeps the rotational speed constant as long as the wind speed is high enough for the turbine to extract power at the set rotational speed, which was the case during the experiment. However, the rotational speed can vary slightly due to the varying small voltage drop across the generator windings during high fluctuations in currents. During this experiment these variations were small enough not to affect

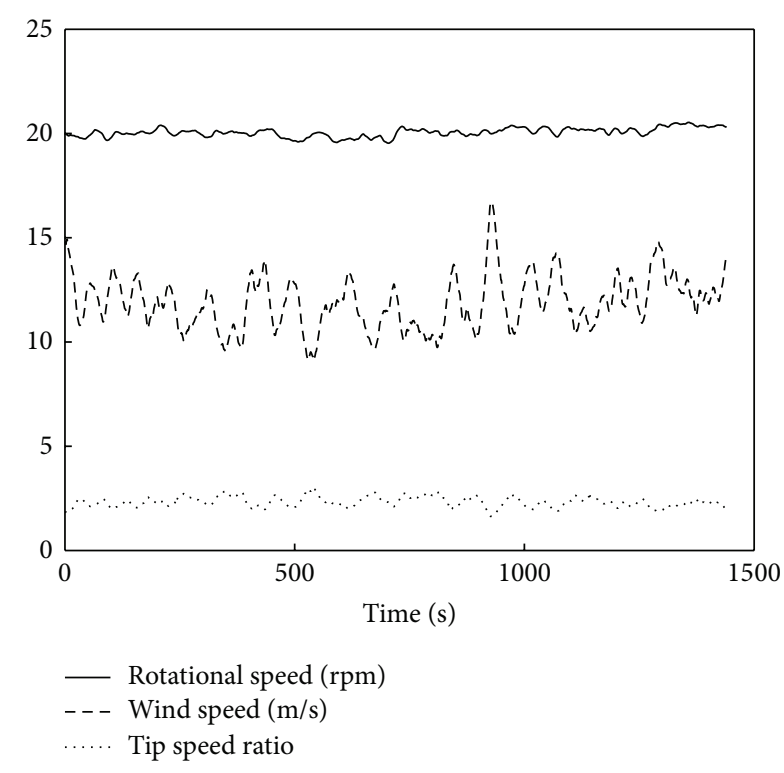

FIGURE 4: The rotational speed, wind speed and tip speed ratio during stall operation.

the experiment, and the rotational speed was measured to give the correct tip speed ratio. During the experiment, the tip speed ratio was kept low, to make the turbine stall and thereby absorb less power. The experiment was only run a limited amount of time since more time was spent on running the turbine at higher tip speed ratio where it would absorb more power.

\section{Results}

Results are shown for about 24 minutes of operation. The control system is able to limit the rotational speed of the turbine even under conditions with high variation in wind speeds, as shown in Figure 4. During this experiment, the mean power delivered from the turbine was $85 \mathrm{~kW}$, the wind speed was between $8 \mathrm{~m} / \mathrm{s}$ and $18 \mathrm{~m} / \mathrm{s}$, and the rotational speed was kept at $20 \mathrm{rpm}$ with a standard deviation of $0.2 \mathrm{rpm}$. The tip speed ratio varied between 1.6 and 3 . The difference between available power in the wind (see (1)) and absorbed DC power in Figure 5 shows that the turbine is operating in stall; that is, the power absorption is stall regulated. A strong gust passes the turbine roughly $950 \mathrm{~s}$ into the experiment, which strongly increases the available power in the wind but does not make a distinguishable impact on the absorbed power. During this gust, the tip speed ratio decreases (moving towards zero on the $C_{P}$ curve in Figure 2) and thereby increases the stall of the turbine. The turbine was not run at an optimal $C_{P}$ regulation during the test of stall operation, since stall occurs at lower tip speed ratios than optimal.

\section{Discussion}

The results from the stall regulation experiment show that it is possible to maintain control of a turbine in strong 


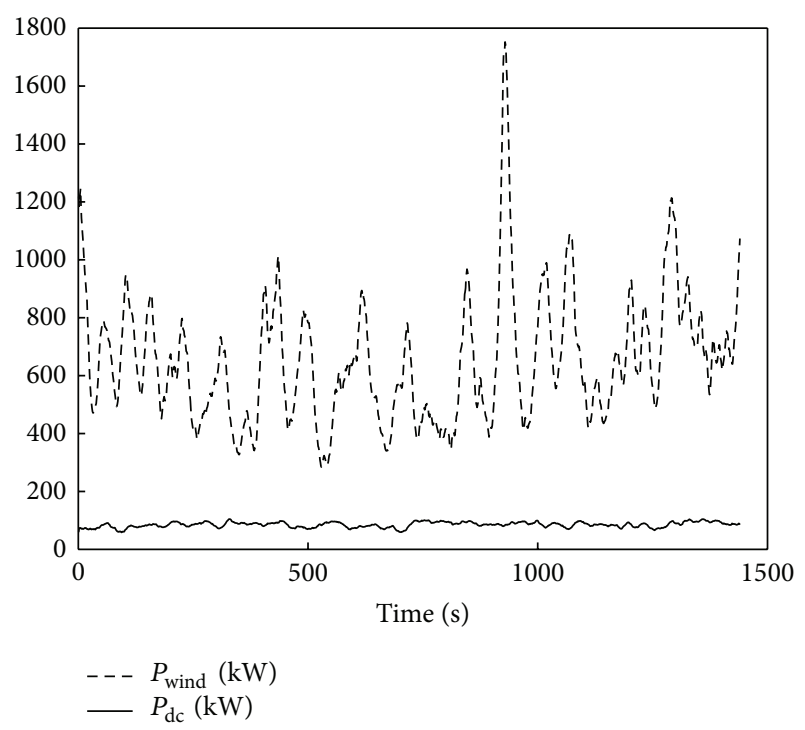

Figure 5: Stall behavior of the turbine. The available power in the wind and the absorbed DC power during the same time interval as in Figure 4.

gusty winds without any mechanical control systems such as pitching of blades. The electrical system can handle the turbine accommodated by passive stall. The intrinsic stall control is effectively used by limiting the rotational speed before the nominal power has been reached. The result implies that as long as the generator voltage can be kept at a desired level during the entire operating span, no other active storm protection is needed. Instead, the design of the control system can be focused towards optimizing power production. In addition, this may simplify the control of a wind farm; if the turbines are working against the same DC-bus, the production can be controlled for the entire farm without the need of individual speed control. However, the results only suggest that this type of wind farm control is possible; experiments are needed to validate the performance of such a wind farm.

\section{Conclusions}

The concept with an all-electric control has been demonstrated. It has been experimentally verified that it is possible to control the turbine rotational speed in gusty winds above nominal wind speed without mechanical control. The rotational speed was kept constant in wind speeds varying from $8 \mathrm{~m} / \mathrm{s}$ to $18 \mathrm{~m} / \mathrm{s}$. Previous results in [10] state that the generator is capable of electrically induced stall, which was verified for the complete wind turbine in this experiment. Long-time measurements are ongoing to find experimental $C_{P^{-}}$and power-curves for the turbine.

\section{Acknowledgments}

This work was conducted within the StandUP for Energy strategic research framework. Acknowledgments are given to
Vertical Wind AB, E.ON, Falkenberg Energy and the Swedish Energy Agency. The Swedish Energy Agency and Vinnova are acknowledged for contributions to the Swedish Centre for Renewable Electric Energy Conversion.

\section{References}

[1] European Wind Energy Association, Wind Energy Factsheets, 2010, http://www.ewea.org/.

[2] G. J. M. Darrieus, "Turbine having its rotating shaft transverse to the flow of the current," United States Patent Office, Patent no. $1835018,1931$.

[3] V. Samsonov and P. Baklushin, "Comparison of different ways for VAWT aerodynamic control," Journal of Wind Engineering and Industrial Aerodynamics, vol. 39, no. 1-3, pp. 427-433, 1992.

[4] A. Hansen and C. Butterfield, "Aerodynamics of HorizontalAxis Wind Turbines," Annual Review of Fluid Mechanics, vol. 25, pp. 115-149, 1993.

[5] J. Ribrant and L. M. Bertling, "Survey of failures in wind power systems with focus on Swedish wind power plants during 19972005," IEEE Transactions on Energy Conversion, vol. 22, no. 1, pp. 167-173, 2007.

[6] J. O. Dabiri, "Potential order-of-magnitude enhancement of wind farm power density via counter-rotating vertical-axis wind turbine arrays," Journal of Renewable and Sustainable Energy, vol. 3, no. 4, Article ID 043104, 12 pages, 2011.

[7] J. Kjellin, S. Eriksson, P. Deglaire, F. Bülow, and H. Bernhoff, "Progress of control system and measurement techniques for a $12 \mathrm{~kW}$ vertical axis wind turbine," in Proceedings of the European Wind Energy Conference \& Exhibition (EWEC '08), Brussels, Belgium, 2008.

[8] J. Kjellin, F. Bülow, S. Eriksson, P. Deglaire, M. Leijon, and H. Bernhoff, "Power coefficient measurement on a $12 \mathrm{~kW}$ straight bladed vertical axis wind turbine," Renewable Energy, vol. 36, no. 11, pp. 3050-3053, 2011.

[9] P. Deglaire, Analytical aerodynamic simulation tools for vertical axis wind turbines [Ph.D. thesis], Uppsala University, 2010.

[10] S. Eriksson, H. Bernhoff, and M. Leijon, "A $225 \mathrm{~kW}$ direct driven PM generator adapted to a vertical axis wind turbine," Advances in Power Electronics, vol. 2011, Article ID 239061, 7 pages, 2011.

[11] IEC, International Electrotechnical Commission, International Standard IEC, 61400-12-1, Power Performance Measurements of Electricity Producing Wind Turbines, 1st edition, 2005. 


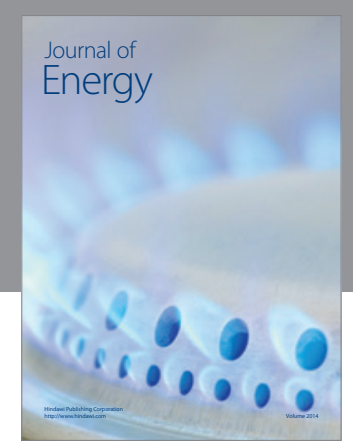

Journal of

Industrial Engineering
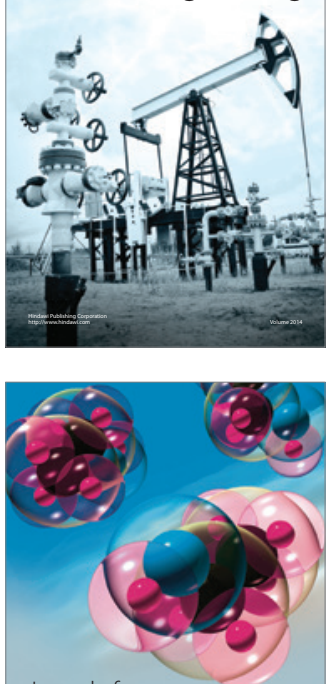

Fuels
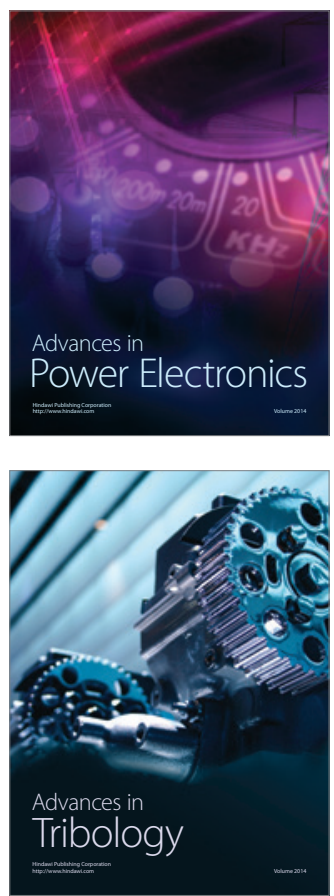

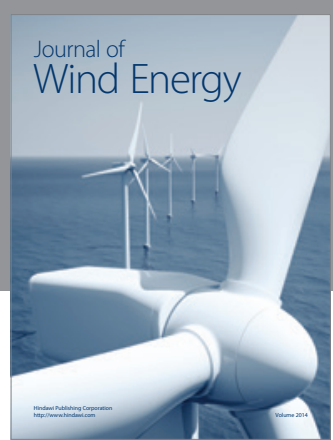

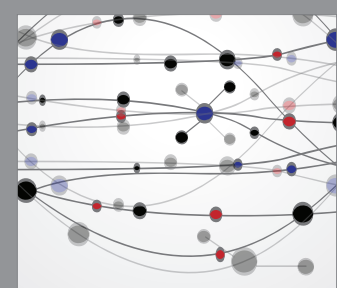

The Scientific World Journal

Submit your manuscripts at http://www.hindawi.com

Journal of

Structures
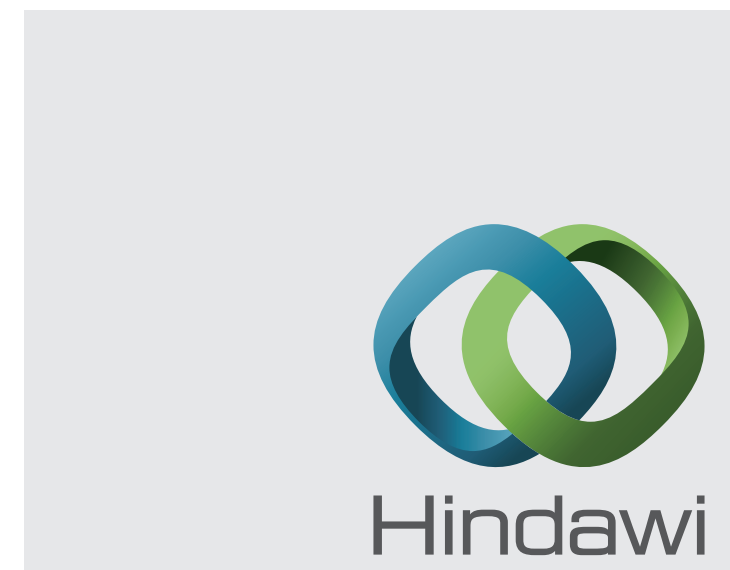

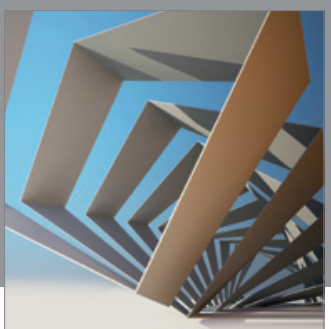

Rotating

Machinery
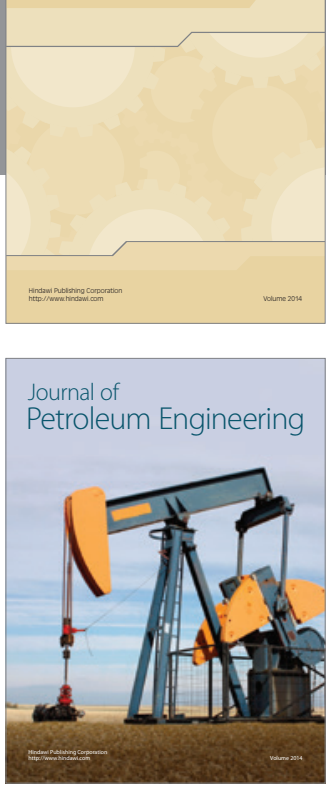

Journal of

Solar Energy
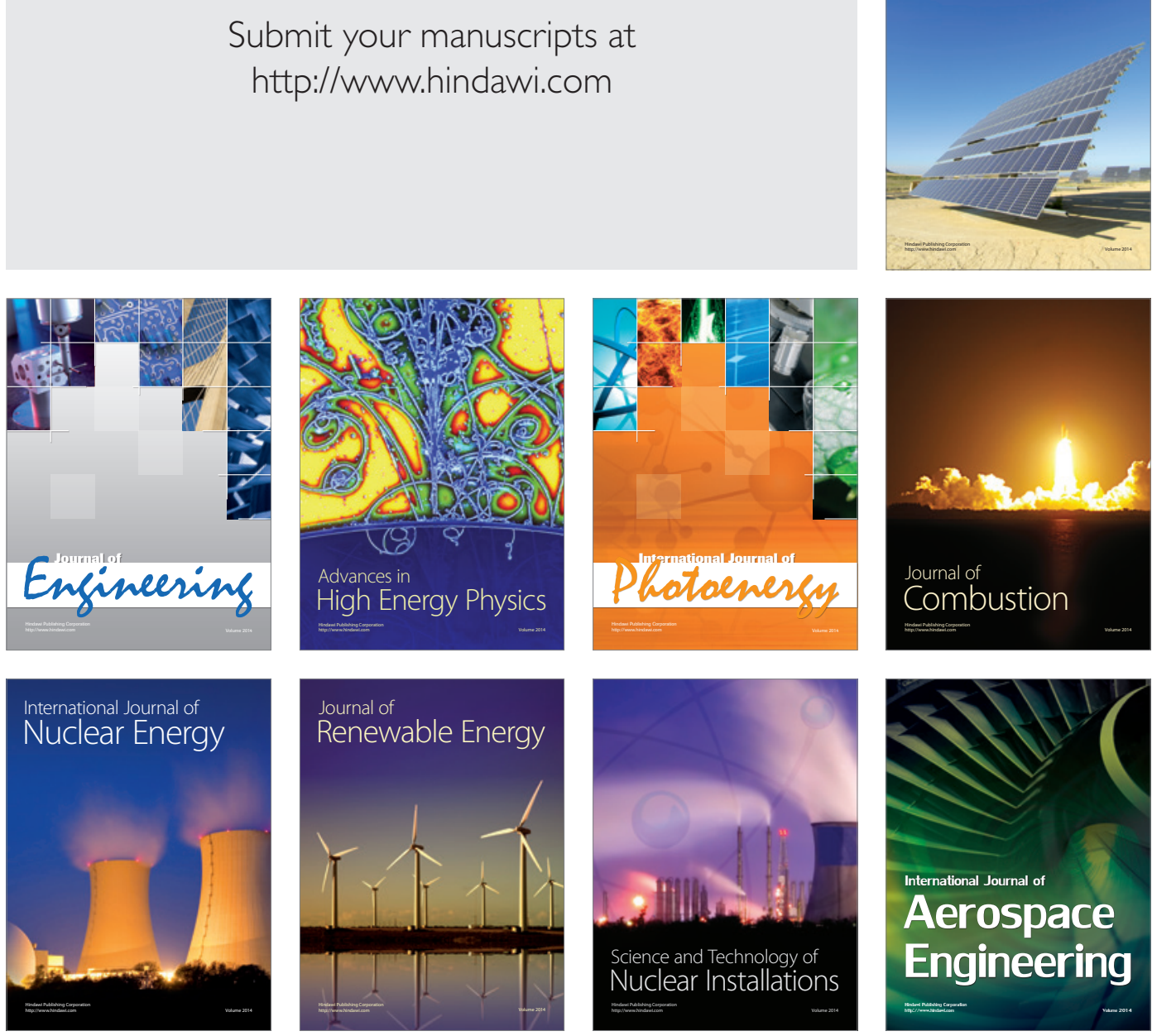